\title{
Simple Lead Angle Adjustment Method for Brushless DC Motors
}

\author{
Bon-Gwan $\mathrm{Gu}^{\dagger}$, Jun-Hyuk Choi* , and In-Soung Jung* \\ ${ }^{\dagger}$ School of Energy Engineering, Kyungpook National University, Daegu, Korea \\ *Intelligent Mechatronics Research Center, Korea Electronics Technology Institute (KETI), Bucheon, Korea
}

\begin{abstract}
This paper presents a simple lead angle adjustment method for brushless DC motors. The proposed method is based on the motor current dynamics analysis during the current commutation interval. With the proposed scheme, the phase current and phase back-EMF voltage are in phase and the BLDC motor and drive system have a high efficiency induced by the reduced copper and conduction losses. Experimental results are shown to validate the proposed method.
\end{abstract}

Key words: BLDC lead angle, Brushless DC motor, Current dynamics analysis

\section{INTRODUCTION}

DC motors have been widely used in a number of low power industrial equipment applications because of their ease of control, low cost and simple torque-speed characteristic. Despite these advantages, dc motor drives have many disadvantages: bulky construction, low efficiency, low reliability and need of maintenance. These are mainly due to the presence of the mechanical commutators and brushes of DC motors [1]. Hence, the demands for high efficiency and compact volume have been motivating factors for the replacement of dc motors with BLDC (Brushless DC) motors. BLDC motors have a number of advantages such as high efficiency, a high power factor, a high power density, low acoustic noise and low maintenance cost since no brushes or commutators are used. Moreover, the rapid growth in solid-state power semiconductor technology has made it increasingly practical to introduce BLDC motor drives [1]-[7].

However, BLDC motors need more complex motor drives when compared with dc motor drives. One of the complicated points is the current lagging problem in high speed drives which is induced by the impedance of the inductance at a high frequency. For this reason, the phase current cannot be built up to a demand level and the motor output power and efficiency decrease in high speed operation. In order to solve this problem,

Manuscript received Aug. 26, 2012; accepted Dec. 24, 2013

Recommended for publication by Associate Editor Dong-Hee Lee.

${ }^{\dagger}$ Corresponding Author: bggu@knu.ac.kr

Tel: +82-10-9357-5667, Fax: +82-53-950-8979, Kyungpook Nat'l Univ.

*Intelligent Mechatronics Research Center, Korea Electronics Technology Institute, Korea

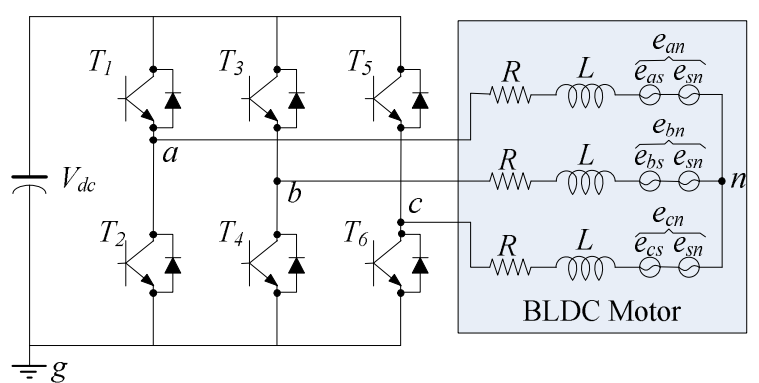

Fig. 1. Equivalent circuit of BLDC motor and inverter.

lead angle injection methods have been utilized [8]-[12].

Tozune [8], Safi [9], Sue [10], Kim [11], and Lee [12] have demonstrated the validity of lead angle injection for high speed BLDC drives. They have verified that the output performance has been improved in the motor current and output torque with lead angle injection and the proposed lead angle adjustment rules.

Tozune [8] proposed a phase advancing circuit which changes the lead angle depending on the motor speed. The circuit is simple and effective for high speeds. However, it is not easy to design the proposed circuit for the entire speed range and for various demand torques. Safi [9] studied the effects of the lead angle on both the speed/torque performance and the phase current with an analytical model. In Sue's model [10], a scaling factor for lead angle calculation is given by experiments. Im [11] presented a maximum torque control method with a lead angle decision rule. In the presented method, it was assumed that the phase currents led to back 


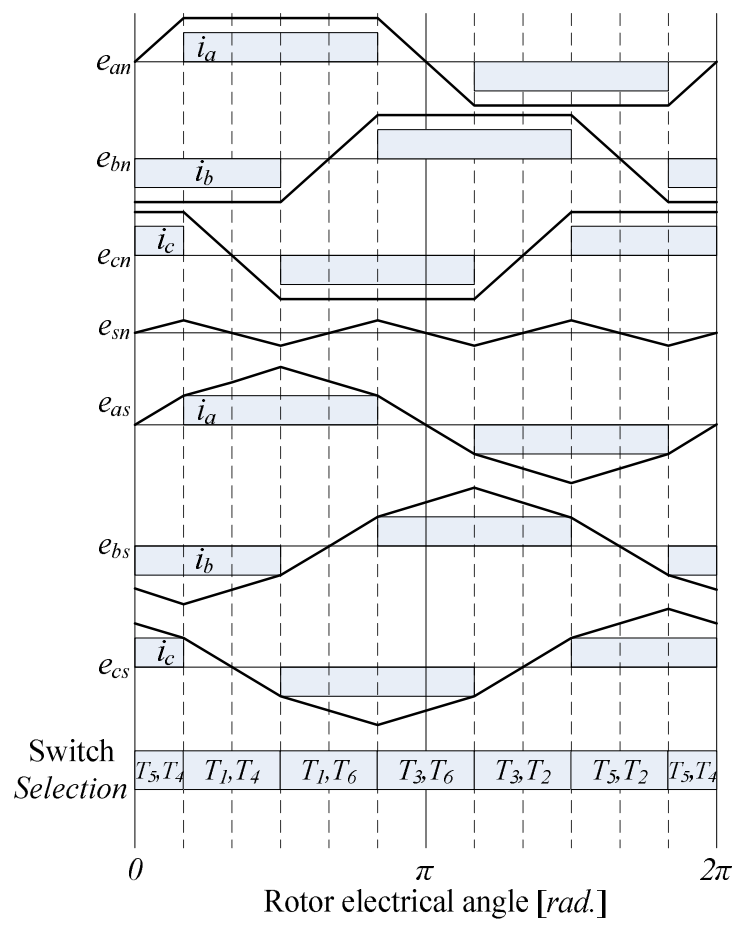

Fig. 2. Plots of phase Back-EMF, phase current and inverter switch signal.

EMFs. However, phase currents in phase with the back-EMFs are better for minimizing copper loss. Lee [12] analyzed the vibration and the electrical characteristics of BLDC motors according to the lead angle. They showed that BLDC motors have lower vibrations and higher torque per ampere with the lead angle injection.

In this paper, a simple lead angle adjustment method is proposed based on simplified BLDC motor current dynamics during the commutation interval. With the proposed method, the motor current and motor back-EMF have an identical phase angle. In addition, the motor and drive system has a low copper loss (high efficiency) and a high motor power.

\section{PRINCIPLE OF A BLDC MOTOR}

Fig. 1 shows the inverter configuration with an equivalent circuit of a BLDC motor. The BLDC motor has a three-phase wye configuration where ' $n$ ' and ' $\mathrm{g}$ ' are the neutral points of the three phase stator winding and the inverter ground. $e_{a n}$ (= $\left.e_{a s}+e_{s n}\right), e_{b n}\left(=e_{b s}+e_{s n}\right)$, and $e_{c n}\left(=e_{c s}+e_{s n}\right)$ denote the $\mathrm{a}, \mathrm{b}$, c-phase back EMF and satisfy $e_{a s}+e_{b s}+e_{c s}=0$. Here, 's' denotes the equivalent neutral point. $e_{s n}$ is the common mode voltage of the phase back EMF. $L$ is the equivalent phase inductance which is the sum of the self and mutual inductance. $R$ and $V_{d c}$ denote the resistance and the DC-link voltage, respectively.

In general, the model of a BLDC motor in terms of the phase variables is represented as follows: (a)

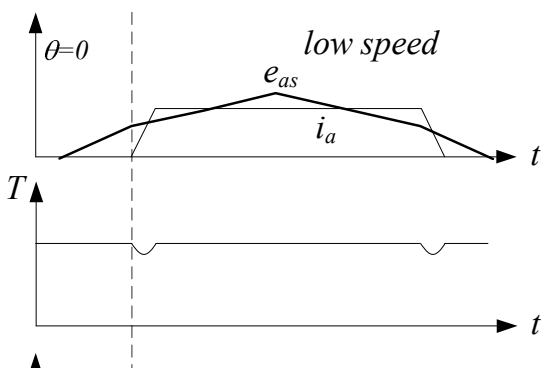

(b)

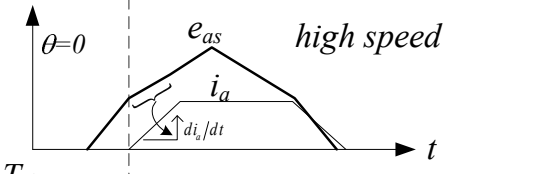

(c)

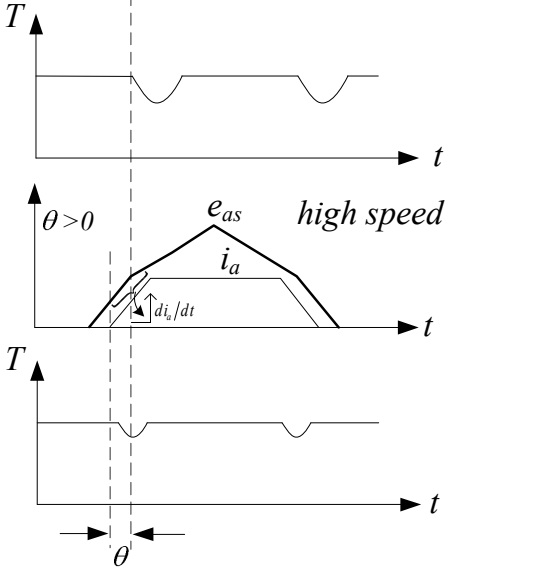

Fig. 3. Waveforms of Back-EMF and phase current (a) at low speed without lead angle injection, (b) at high speed without lead angle injection, (c) at high speed with lead angle injection.

$$
L \frac{d}{d t}\left[\begin{array}{l}
i_{a} \\
i_{b} \\
i_{c}
\end{array}\right]=-R\left[\begin{array}{l}
i_{a} \\
i_{b} \\
i_{c}
\end{array}\right]+T\left[\begin{array}{l}
v_{a n}-e_{a n} \\
v_{b n}-e_{b n} \\
v_{c n}-e_{c n}
\end{array}\right],
$$

where $T=\frac{1}{3}\left[\begin{array}{ccc}2 & -1 & -1 \\ -1 & 2 & -1 \\ -1 & -1 & 2\end{array}\right]$.

$v_{a n}, v_{b n}$, and $v_{c n}$ denote the BLDC motor phase voltages; and $i_{a}$, $i_{b}$, and $i_{c}$ denote the phase motor currents, respectively. $T$ is a matrix which removes the common mode voltage signals. Due to the three phase three wire configuration, the phase currents satisfy $i_{a s}+i_{b s}+i_{c s}=0$. Hence, the common mode voltages can not affect the phase current dynamics and $T$ is presented in (2) to eliminate the common mode voltages. It has been assumed that the phase back-EMFs have half-wave symmetrical waveforms and that they also have the same magnitude for the three phase windings with $2 \pi / 3$ [rad.] phase shift each other. In addition, the motor torque is achieved to demand the level by utilizing the voltage controlled uni-polar PWM strategy. From the last term of (1), the applied voltage can be represented as follows: 


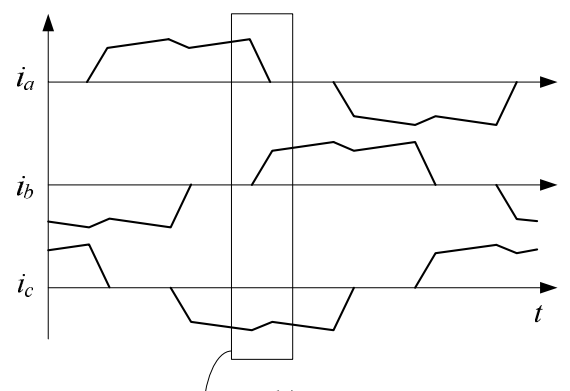

(a)

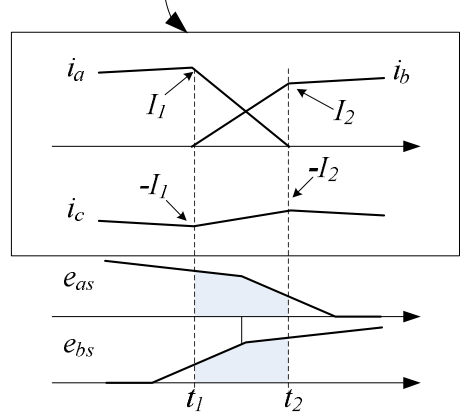

(b)

Fig. 4. Phase current waveform (a) for one period, (b) for excitation winding switch with optimal lead angle.

$$
T\left[\begin{array}{c}
v_{a n}-e_{a n} \\
v_{b n}-e_{b n} \\
v_{c n}-e_{c n}
\end{array}\right]=\left[\begin{array}{l}
v_{a s} \\
v_{b s} \\
v_{c s}
\end{array}\right]-\left[\begin{array}{l}
e_{a s} \\
e_{b s} \\
e_{c s}
\end{array}\right],
$$

$v_{a s}, v_{b s}$, and $v_{c s}$ denote the applied inverter phase voltage without the common mode voltage. From (1) and (2), the BLDC motor can be represented as:

$$
L \frac{d}{d t}\left[\begin{array}{l}
i_{a} \\
i_{b} \\
i_{c}
\end{array}\right]=-R\left[\begin{array}{l}
i_{a} \\
i_{b} \\
i_{c}
\end{array}\right]+\left[\begin{array}{l}
v_{a s} \\
v_{b s} \\
v_{c s}
\end{array}\right]-\left[\begin{array}{l}
e_{a s} \\
e_{b s} \\
e_{c s}
\end{array}\right]
$$

Ideally, a BLDC motor is driven by a three-phase inverter with the DC current excitation applied over 120 degrees which is called the six-step commutation algorithm. At any period, only two of three phases are excited where the motor current flows into one phase and then out another. For instance, when a-phase and b-phase conduct current, c-phase is not excited and the phase current is zero. Fig. 2 shows plots of the phase back-EMFs of a BLDC motor and the 120 degree excitation rule by an inverter with a zero commutation interval.

At a low speed, the current waveform is close to an ideal rectangular waveform with a phase voltage applied during each phase-conduction time interval to force the demand current excitation. During each interval, the applied phase voltage exceeds the back-EMF by an amount equal to the voltage drop across the winding resistance. However, the inductive reactance of the winding results in a significant phase delay at a high speed since the one period conduction time is shorter. The output torque of the drive also decreases since the phase

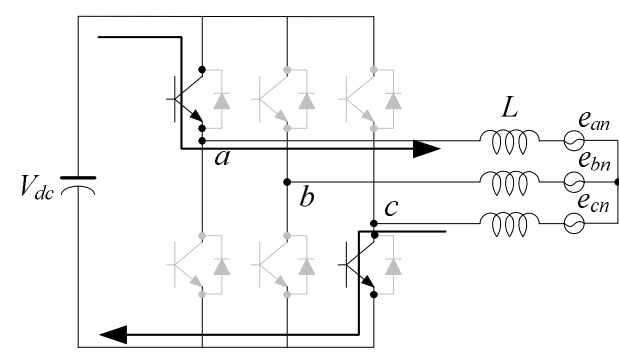

(a) $t<t_{1}$

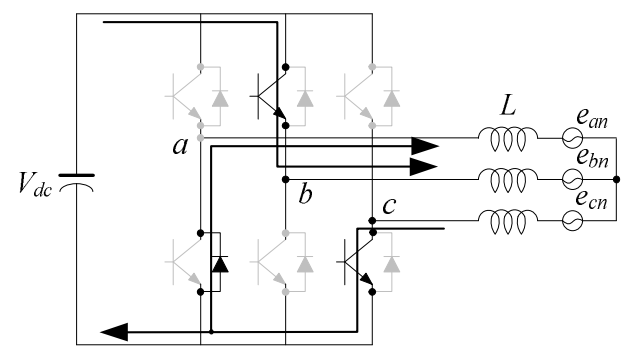

(b) $t_{1}<t<t_{2}$

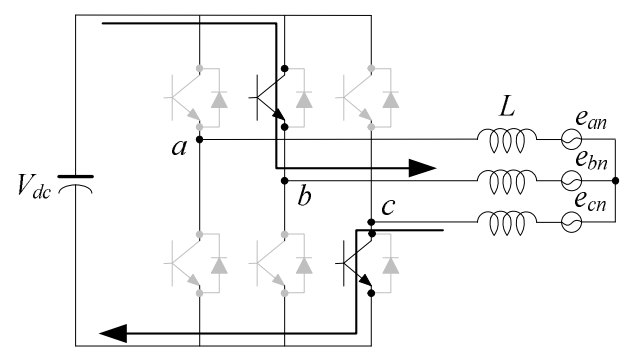

(c) $t_{2}<t$

Fig. 5. Current conduction for (a) $t<t_{1}$, (b) $t_{1}<t<t_{2}$, (c) $t_{2}<t$.

current magnitude is out of phase with the back-EMF by the phase delay. This current excitation delay can be compensated to some extent by injecting each phase voltage earlier. This is called lead angle adjustment. With lead angle adjustment, the phase currents in the motor windings are allowed to be built up in advance.

Fig. 3 shows plots of the back-EMF and phase current waveforms at (a) a low speed and at (b), (c) a high speed, where $\theta$ denotes the lead angle. At a low speed, shown in Fig. 3 (a), the phase current is built up to the current demand quickly since the phase back EMF and the phase delay by the motor inductance are low. However, at a high speed, the phase back-EMF and the phase delay by the motor inductance are quite high. As shown in Fig. 3 (b), the phase current time delay from zero to the current demand has a large portion of the overall time interval. This reduces the output torque and power, and increases the torque ripple. Hence, by injecting the phase voltage in advance, as shown in Fig. 3 (c), the current level reaches its current demand earlier, and the current delay can be compensated easily. Moreover, the low back EMF at the commutation start increases di/dt and reduces the commutation 
TABLE I

Integration Results of Phase Back EMFs for Three Different SHAPES

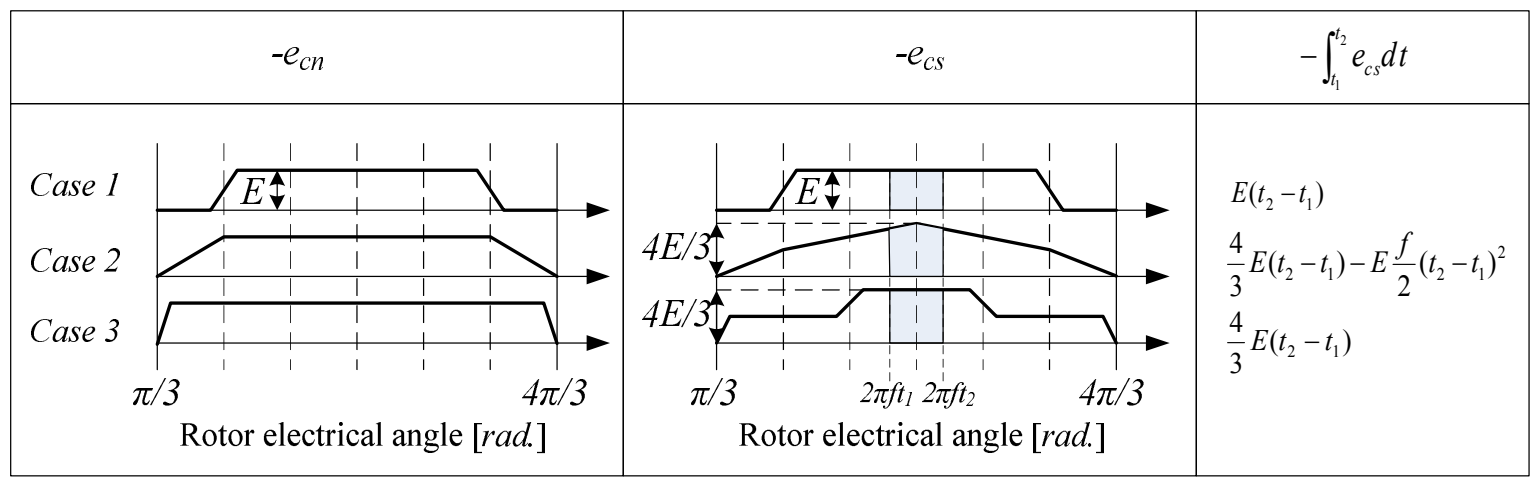

time.

The lead angle represents how early the phase voltage is injected. As the lead angle $\theta$ increases, the phase current excites the winding earlier. When each phase current has the same phase angle as each phase back EMF, the BLDC motor needs a lower demand current for a given torque demand and achieves a high efficiency due to the reduced copper loss. In the next section, a mathematical BLDC motor model defining a simple lead angle, which makes each phase current phase have the same phase as each phase back EMF, is presented.

\section{LEAD ANGLE AdJUSTMENT METHOD}

Fig. 4 and Fig. 5 show the phase current waveforms and drive switching states of the current commutation interval when the excitation winding changes from 'a-phase to c-phase' to 'b-phase to c-phase' for $t_{1}<t<t_{2} . t_{1}$ and $t_{2}$ are the current commutation start and end times. $I_{1}$ and $I_{2}$ satisfies $i_{a s}\left(t_{l}\right)=$ $-i_{c s}\left(t_{1}\right)=I_{1}$ and $i_{b s}\left(t_{2}\right)=-i_{c s}\left(t_{2}\right)=I_{2}$. After the T1 switch turns off, the freewheeling diode of $\mathrm{T} 2$ start to conduct $i_{a}$ until it decreases to zero. At the same time, T3 turns on and $i_{b}$ increase to $I_{2}$. By assuming that T1 T6 are ideal transistors, the phase voltage for $t_{1}<t<t_{2}$ can be derived as:

$$
\left[\begin{array}{lll}
v_{a s} & v_{b s} & v_{c s}
\end{array}\right]^{T}=D V_{d c}\left[\begin{array}{lll}
1 / 3 & -2 / 3 & 1 / 3
\end{array}\right]^{T}
$$

where $D$ denotes the duty ratio. The phase voltage (4) is obtained based on the mean applied voltage with an assumption of a constant duty ratio $D$ during the commutation interval. With (3) and (4), the phase current dynamics can be obtained as:

$$
\begin{aligned}
& L \frac{d i_{a}}{d t}=-R i_{a}-\frac{D V_{d c}}{3}-e_{a s} \\
& L \frac{d i_{b}}{d t}=-R i_{b}+\frac{2 D V_{d c}}{3}-e_{b s}
\end{aligned}
$$

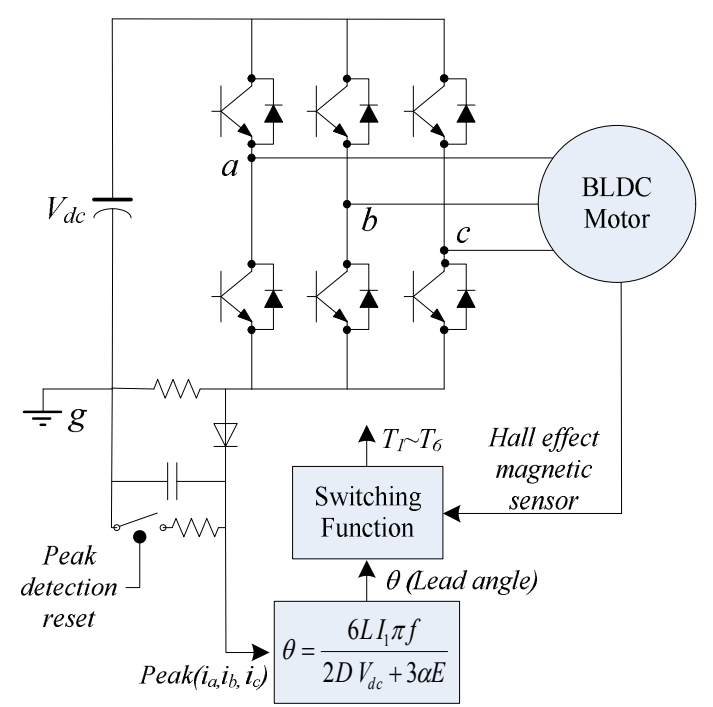

Fig. 6. Control block diagram with proposed method.

$$
L \frac{d i_{c}}{d t}=-R i_{c}-\frac{D V_{d c}}{3}-e_{c s}
$$

Applying the Euler method to (5)-(7), the following is obtained:

$$
\begin{aligned}
L I_{1} & =\left(\frac{R I_{1}}{2}+\frac{D V_{d c}}{3}\right)\left(t_{2}-t_{1}\right)+\int_{t 1}^{t 2} e_{a s} d t \\
L I_{2} & =\left(-\frac{R I_{2}}{2}+\frac{2 D V_{d c}}{3}\right)\left(t_{2}-t_{1}\right)-\int_{t 1}^{t 2} e_{b s} d t \\
L\left(I_{1}-I_{2}\right) & =-\left(\frac{R\left(I_{1}+I_{2}\right)}{2}+\frac{D V_{d c}}{3}\right)\left(t_{2}-t_{1}\right)-\int_{t 1}^{t 2} e_{c s} d t
\end{aligned}
$$

If the lead angle which makes the phase current and the phase back EMF is allowed to have the same phase angle, the integration of $e_{a}$ and $e_{b}$ over the commutation interval $\left[t_{l}, t_{2}\right]$ have the same magnitude as shown in the shaded region of Fig. 


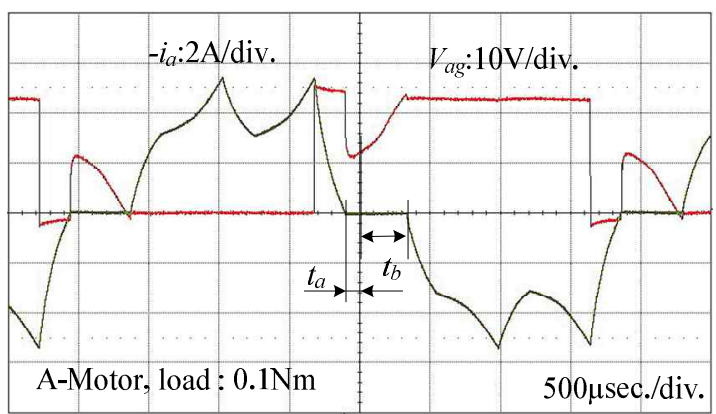

(a)

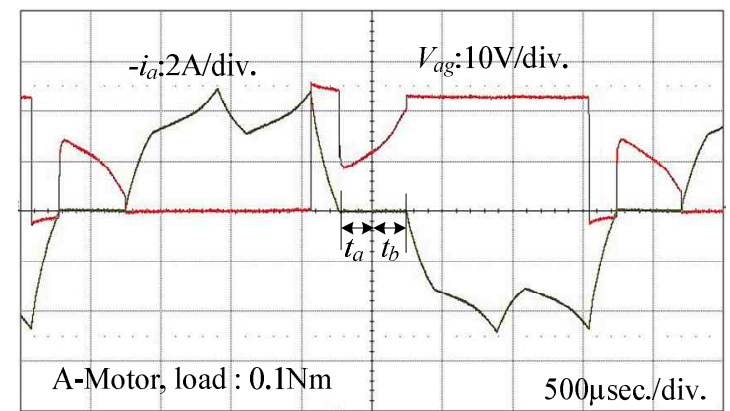

(b)

Fig. 7. Measured voltages and currents comparison of A-motor under $0.1 \mathrm{Nm}$ load torque at $2530 \mathrm{rpm}$, and $D=1$, (a) without lead angle injection, (b) with proposed lead angle adjustment method.

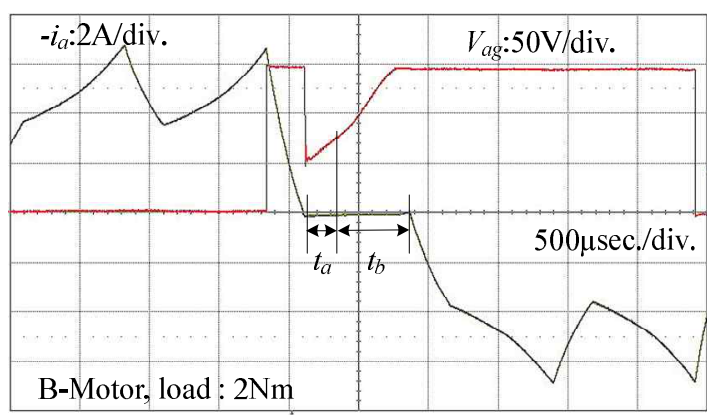

(a)

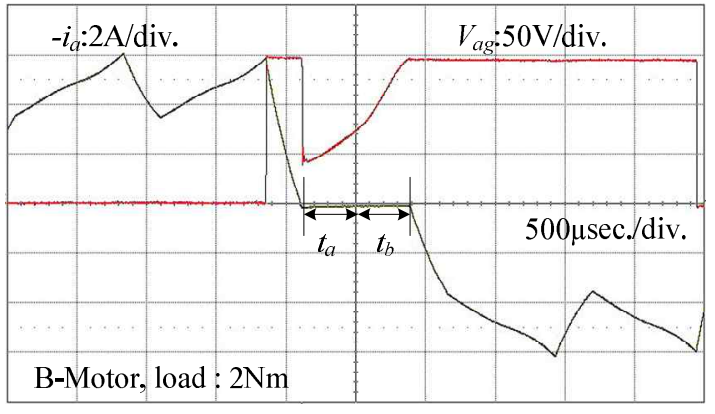

(b)

Fig. 8. Measured voltages and currents comparison of B-motor under $2 \mathrm{Nm}$ load torque at $3750 \mathrm{rpm}$ and $D=1$, (a) without lead angle injection, (b) with proposed lead angle adjustment method.

4 (b). Hence, $\int_{t 1}^{t 2} e_{a s} d t-\int_{t 1}^{t 2} e_{b s} d t=0$. By summing (8) and (9), the commutation time $t_{2}-t_{l}$ is obtained as

$$
t_{2}-t_{1}=\frac{L\left(I_{1}+I_{2}\right)}{D V_{d c}+R\left(I_{1}-I_{2}\right) / 2}
$$

Assuming $R\left(I_{I}-I_{2}\right)<<D V_{d c}$, the commutation time can be simply represented as follows:

$$
t_{2}-t_{1} \approx \frac{L\left(I_{1}+I_{2}\right)}{D V_{d c}}
$$

To obtain the lead angle from (12), the values of $I_{1}$ and $I_{2}$ are needed. $I_{l}$ can be obtained easily by measuring $i_{a}$ just before $\mathrm{T} 1$ turns off or the maximum value of the DC link current. $I_{2}$ can be measured also. However, it is not easy to measure $I_{2}$ since the precise measurement timing $t_{2}$ is hardly defined without $I_{2}$. Hence, the calculated value from (10) and (12) is utilized. To obtain $I_{2}$, the last term $\int_{t 1}^{t 2} e_{c s} d t$ of (10) is difficult to calculate, since it depends on the shape of the phase back EMFs. In Table I, $\int_{t 1}^{t 2} e_{c s} d t$ is represented for three different shapes of the back EMF, where $E$ and $f$ denote the peak phase back EMF of $e_{c n}$ and the electrical frequency of the speed. For $t_{1}<t<t_{2}$ and $R\left(I_{1}+I_{2}\right)<<D V_{d c}, I_{2}$ can be estimated as:

Case 1: $I_{2}=\frac{4 D V_{d c}+3 E}{2 D V_{d c}-3 E} I_{1}$

Case $2: I_{2}=\frac{2 D V_{d c}\left(\begin{array}{l}-D V_{d c}+2 E \\ -\sqrt{\left(D V_{d c}-2 E\right)^{2}-3 f L E I_{1}}\end{array}\right)}{3 f L E}-I_{1}$

Case 3: $I_{2}=\frac{2 D V_{d c}+2 E}{D V_{d c}-2 E} I_{1}$

For case $2, I_{2}$ is too complicated to use in the application. Therefore, $\alpha$ is defined to satisfy $1 \leq \alpha \leq 4 / 3$. If $\alpha$ is 1 or $4 / 3$, it is the same with case 1 or case 3 . With (14) and (12), the lead angle can be obtained as follows:

$$
\theta=\frac{6 L I_{1} \pi f}{2 D V_{d c}+3 \alpha E}
$$

By injecting the proposed lead angle (16), the phase back EMF 

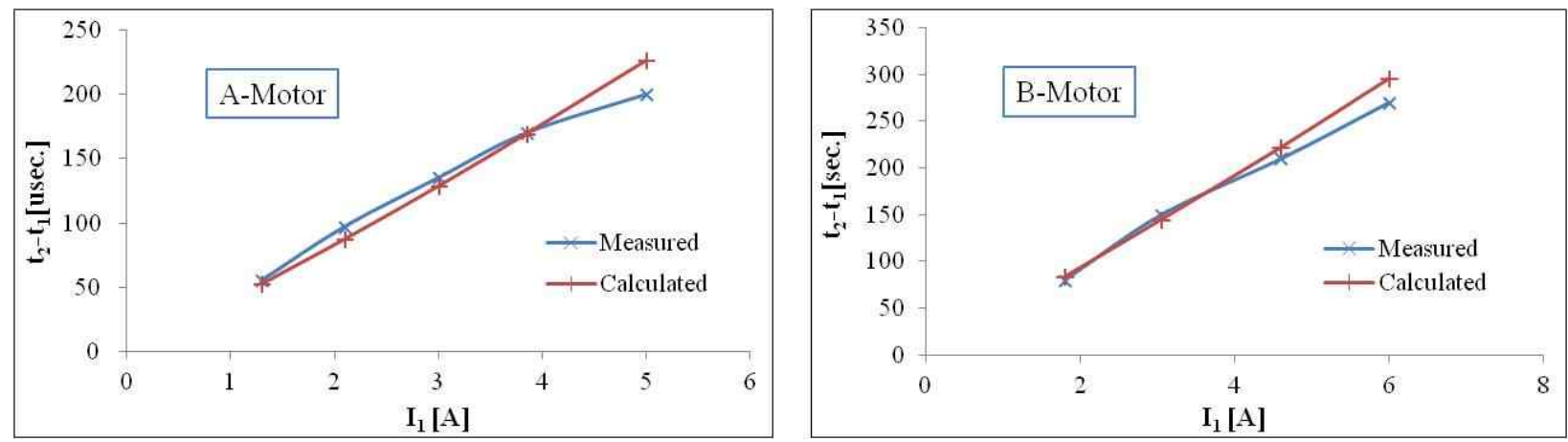

(a)
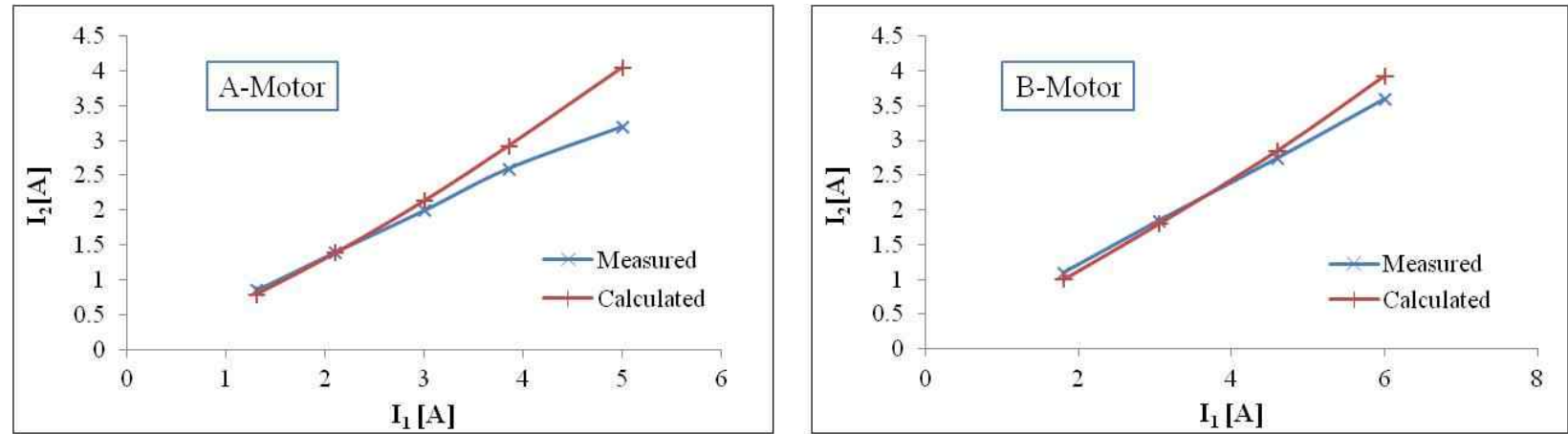

(b)

Fig. 9. Comparison of measured value and calculated value of, (a) $t_{2}-t_{l}$ by eq.(12) and measurement, (b) $I_{2}$ by eq.(14) and measurement $(D=1)$.

and the phase current have identical phase angles and the motor efficiency and the output power increase.

\section{EXPERIMENTAL RESULTS}

In order to verify the proposed lead angle adjustment scheme, experiments are carried out with two BLDC motors and inverters having different voltage and power ratings. To exclude the PWM effect, set $\mathrm{D}=1$. The parameters of the BLDC motors and inverters which are utilized in this study are summarized in Table II. Fig. 6 shows a block diagram of the proposed lead angle method. At the bottom of the inverter DC link capacitor, the shunt resistor and peak current detector are installed to measure $I_{l}$. The peak current detector is reset at every commutation. The measured peak current and hall sensor signals are utilized to generate the proposed lead angle.

Fig. 7 and Fig. 8 show the measured voltage and current plots with the A-motor (2530rpm) and B-motor (3750rpm). Fig. 7 (a) and Fig. 8 (a) are without the lead angle injection while Fig. 7 (b) and Fig. 8 (b) are with the proposed lead angle adjustment scheme, where $V_{a g}$ denotes the a-phase voltage between the leg and the inverter ground, and $t_{a}$ and $t_{b}$ denote the time intervals from the commutation start time $t_{1}$ to $e_{a}(t)=0$ $\left(V_{a g}(\mathrm{t})=V_{d c} / 2\right)$ and from $e_{a}(t)=0$ to the commutation end time $t_{2}$ $\left(i_{a}(t)=0\right)$. Since three-phase three-wire BLDC motors are utilized, the phase back EMF cannot be directly measured.
TABLE II

MOTORS AND INVERTERS PARAMETERS

\begin{tabular}{|c|c|c|}
\hline \multirow{2}{*}{ Items } & \multicolumn{2}{|c|}{ Specification } \\
\cline { 2 - 3 } & A-Motor & B-Motor \\
\hline Output power[W] & 25 & 500 \\
\hline Number of Poles & 12 & 8 \\
\hline Resistance $[\Omega]$ & 1.4 & 1.1 \\
\hline Inductance $[\mathrm{mH}]$ & 0.3 & 4.5 \\
\hline DC-link voltage $[\mathrm{V}]$ & 12 & 150 \\
\hline
\end{tabular}

Hence, during the commutation time, the back EMF zero crossing event is observed at $V_{a g}=V_{d c} / 2$ [4]. When $t_{a}$ and $t_{b}$ have the same value, the phase current and the back EMF are in phase. In Fig. 7 (a) and Fig. 8 (a), the phase current generates the output torque to overcome the load torque. Without the lead angle adjustment, $t_{b}$ is longer than $t_{a}$, which means that the phase current lags the back EMF. However, in Fig. 7 (b) and Fig. 8 (b), the proposed lead angle adjustment method makes $t_{a}$ and $t_{b}$ be equal by injecting the calculated lead angle with (16). With the proposed lead angle adjustment scheme, the phase currents are in phase with the back EMFs. Since the maximum output torque generation occurs when the phase currents are in phase with the back EMFs, the overall phase currents especially in terms of the peak values are lower than in Fig. 7 (a) and Fig. 8 (a). 


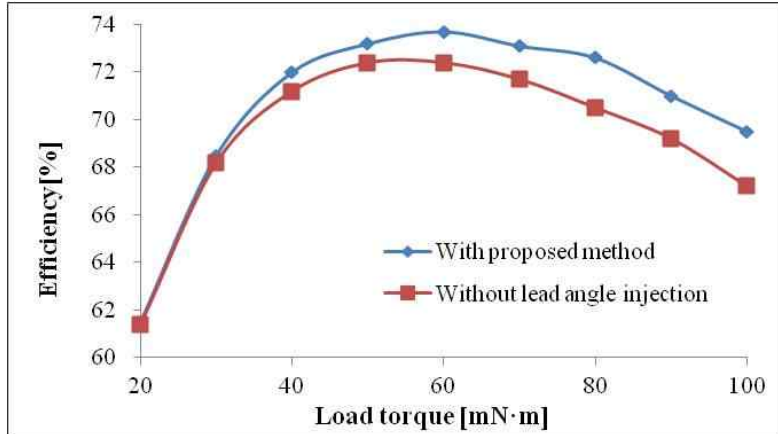

(a)

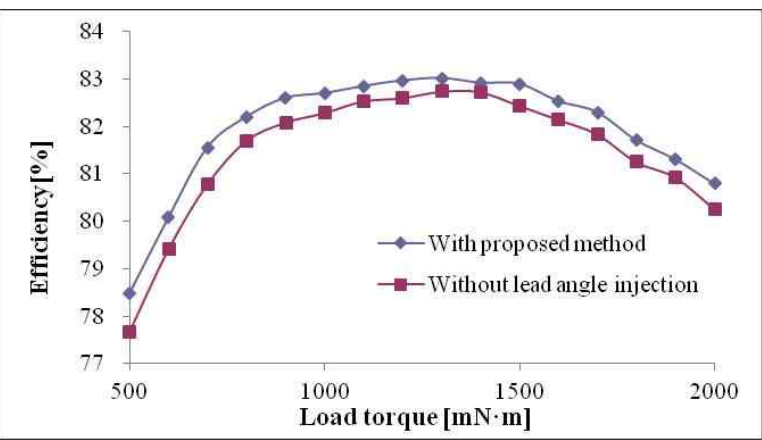

(b)

Fig. 10. Motor and drive efficiency measurement results of (a) A-motor and (b) B-motor $(D=1)$.

Fig. 9 shows a comparison of the measured and calculated values of (a) $t_{2}-t_{1}$ and (b) $I_{2}$ versus $I_{1}$. The calculated values are by (12) and (14). In Fig. 9 (a) and (b), the calculated value has a very precise result for a low $I_{l}$. In a high $I_{l}$, the phase inductances decrease by the core saturation and the winding resistor is not negligible. The calculated and measured values have to some differences.

Fig. 10 shows the efficiency results of the motors and inverters without lead angle injection and with the proposed method. With the proposed lead angle adjustment method, the efficiency is higher. This mainly comes from the decreases in both the copper losses in the BLDC motors and the conduction losses in the inverters.

\section{CONCLUDING REMARKS}

In this paper, a lead angle adjustment scheme has been proposed. The proposed scheme is based on the simplified mathematical model. The calculated lead angle was obtained by utilizing only the information of the input DC-link voltage and motor inductance. With the proposed scheme, the motor current and motor back-EMF are in phase and the BLDC motor and drive system have low copper losses and a high efficiency induced by the low motor currents. Experimental results have validated the effects of the proposed method.

\section{ACKNOWLEDGMENT}

This work was supported by the Energy Efficiency \& Resource Core Technology Program of the Korea Institute of Energy Technology Evaluation and Planning (KETEP) granted financial resource from the Ministry of Trade, Industry \& Energy, Republic of Korea. [2012T100201607, Development of High-capacity Power Modules for Green Commercial Vehicle]

\section{REFERENCES}

[1] M. Zeraoulia, M.E.H. Benbouzid, and D. Diallo, "Electric motor drive selection issues for HEV propulsion systems : A comparative study," IEEE Trans. Veh. Technol., Vol. 55, No. 6, pp. 1756-1764, Nov. 2006.

[2] B. K. Lee, and M. Ehsani, "Advanced simulation model for brushless DC motor drives," Electric Power Components and Systems, Vol. 31, No. 9, pp. 841-868, 2003.

[3] J. Shao, D. Nolan, M. Teissier, and D. Swanson, "A novel microcontroller-based sensorless brushless DC (BLDC) motor drive for automotive fuel pumps," IEEE Trans. Ind. Appl., Vol. 39, No. 6, pp. 1734-1740, Nov./Dec. 2003.

[4] J. Shao, "An improved microcontroller-based sensorless brushless DC (BLDC) motor drive for automotive applications," IEEE Trans. Ind. Appl., Vol. 42, No. 5, pp. 1216-1221, Sep./Oct. 2006.

[5] N. Bianchi, S. Bolognani, and F. Luise, "High speed drive using a slotless PM motor," IEEE Trans. Power Electron., Vol. 21, No. 4, pp. 1083-1090, Jul. 2006.

[6] M. Yilmaz, R.N. Tuncay, O. Ustun, and T.P. Krein, "Sensorless control of brushless dc motor based on wavelet theory," Electric Power Components and Systems, Vol. 37, No. 10, pp.1063-1080, 2009.

[7] B. Singh and V. Bist, "Improved power quality IHQRR-BIFRED converter fed BLDC motor drive," Journal of Power Electronics, Vol. 13, No. 2, pp. 256-263, Mar. 2013.

[8] A. Tozune and T. Takeuchi, "Improvement of torque-speed characteristics of brushless motor by automatic lead angle adjustment," IPEMC 2004, Vol. 2, pp. 583-587, 2004.

[9] S. K. Safi, P. P. Acarnley, and A. G. Jack, "Analysis and simulation of the high-speed torque performance of brushless DC motor drives," in Proc. IEE Electr. Power Appl., Vol. 142, No. 3, pp. 191-200, 1995.

[10] S. M. Sue, K. L. Wu, J.S. Syu, and K.C. Lee, "A phase advanced commutation scheme for IPM-BLDC motor drives," ICIEA 2009, pp. 2010-2013, 2009.

[11] W. S. Im, J. P. Kim, J. M. Kim, and K. R. Baek, "Torque maximization control of 3-phase BLDC motors in the high speed region," Journal of Power Electronics, Vol. 10, No. 6, pp. 713-723, Nov. 2010.

[12] S. J. Lee, J. P. Hong, and W. K. Jang, "Characteristics comparison of BLDC motor according to the lead angles," VPPC2012, pp. 879-883, 2012. 


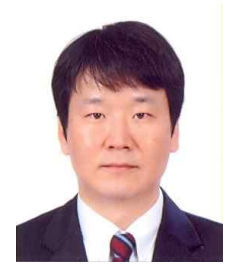

Bon-Gwan Gu was born in Daegu, Korea. He received his B.S. degree in Electronics Engineering from Kyungpook National University, Daegu, Korea, in 1998, and his M.S. and Ph.D. degrees in Electrical Engineering from the Pohang University of Science and Technology (POSTECH), Pohang, Korea, in 2000 and 2005, respectively. From 2005 to 2007, he was with LG Electronics, Seoul, Korea. From 2008 to 2014, he worked as a Managerial Researcher at the Korea Electronics Technology Institute, Bucheon, Korea. In 2014, he joined Kyungpook National University as an Assistant Professor in the School of Energy Engineering. His current research interests include AC motor control, DC-DC converters, and PWM converter/inverter systems.

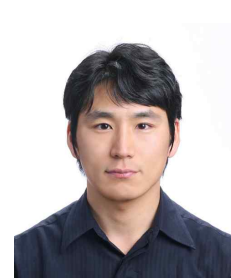

Jun-Hyuk Choi was born in Daegu, Korea, in 1974. He received his M.S. and Ph.D degrees in Electrical and Electronic Engineering, Sungkyunkwan University, Suwon, Korea, in 2003 and 2014. Since 2003, he has been with the Korea Electronics Technology Institute (KETI), Bucheon, Korea. His current research interests include power electronics and motor control systems.

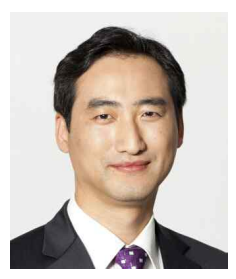

In-Soung Jung was born in Korea, on March 10, 1971. He received his B.S., M.S. and Ph.D. degrees in Electrical Engineering from Hanyang University, Seoul, Korea, in 1993, 1995 and 2000, respectively. Since 2000, he has been with the Korea Electronics Technology Institute (KETI), Bucheon, Korea $\mathrm{He}$ is presently the director of the Intelligent Mechatronics Research Center at KETI. His current research interests include the electromagnetic design of electric machines and motor control. He is a Senior Member of the KIEE and IEEE. 